العلاقة بين بعض المتغير ات(البايو كينماتيكية) و الانجاز للمرحلة النهائية بفعالية رمي الرمايو

د.سيروان كريم عبد م.م.فريدون حسن م.م. جوان زرار فتح الله عثمان الله جامعة صلاح الدين / كلية التربية الرياضية

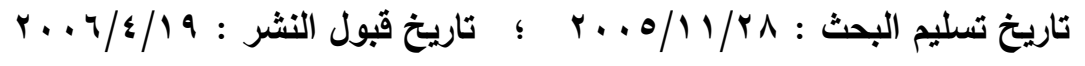

$$
\text { ملخص البحث : }
$$

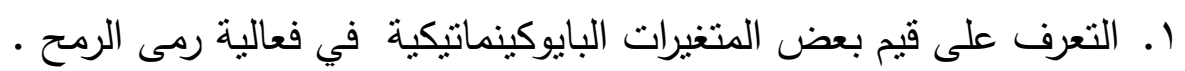

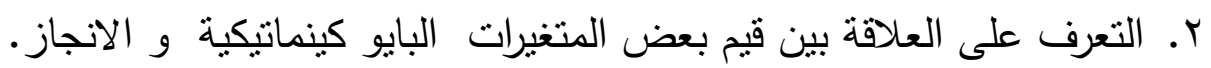

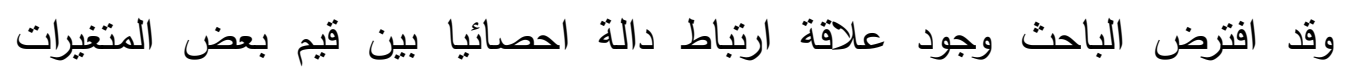

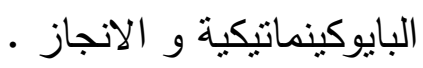
اجريت الدراسة على عينة قوامها (0) لاعبين الاوائل في بطولة الاندية للثباب لالعاب

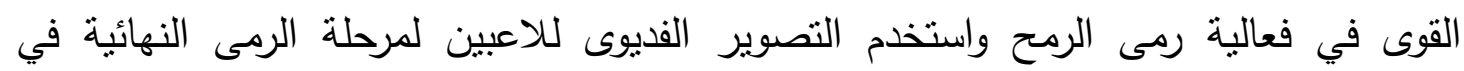

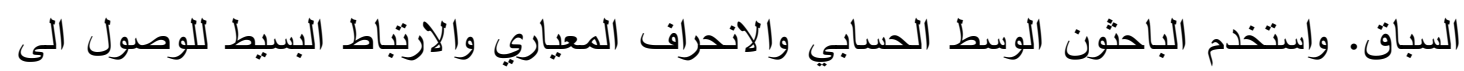
النتائج • وقد أسفرت الدراسة الى الاستتناجات الآتية :

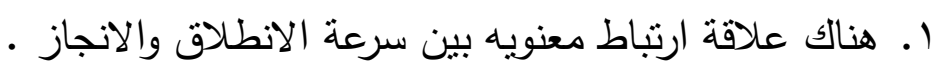
r. عدم وجود علاقة ارتباط معنوية لكل من(زاوية الانطلاق وارتفاع نقطة الانطلاق) مع العابه

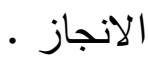

r. وجود علاقة ارتباط معنوية لكل من(طول ،زمن ،سرعة) خطوة الارتكازمع الانجاز .

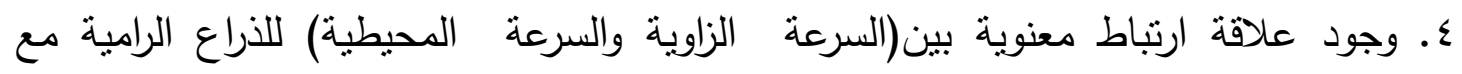

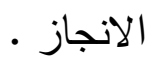
0. عدم وجود علاقة ارتباط معنوية بين زاوية ثني الجذع مع الانجاز • 


\title{
The analysis of biokenamatical of some variables in javelin throw activity
}

\author{
Dr. Serwan K . Abdulah Farydoon H. authman Jwan Z. Z.Fatehllah \\ University of Slahaldeen - College of Sport Education
}

\section{Abstract:}

\section{Aim of study}

1. to identify some values of biokenamatical variables in javelin throw activity .

2. to identify the relationship between biokenamatical variables and performance .

\section{hypothesis}

- there is a statistical significant correlation between some biokenamatical variables and performance .

\section{methodlogy}

- a sample of (5) players of youth clubs championship of track and field in javelin throw activity .

- the study was analyzed by using video tape

- certain statistical methods were used .

\section{results and recommendations}

on the basis of the analysis of the data, the following conclusion were presented

- there is a significant correlation between starting speed and performance .

- there was no significant correlation between starting angle and the height of starting point with performance .

- there is a significant correlation in variables of (length, time and speed) of pivot point .

- there is a significant correlation of angle speed and speed of throwing arm with performance .

- there was no significant correlation in variables of bending trank angle with performance. 
شهد العالم تطورا سريعا في العاب القوى بعد ان وضعت الدول المتقدمة كل امكانياتها

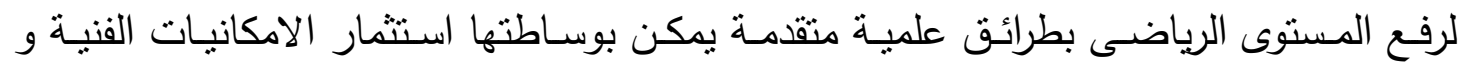
البدنية الرياضية كافة ، و علم الميكانيك الحيوية وهو علم محكم بقوانين ثابتة ومحددة يتمركز

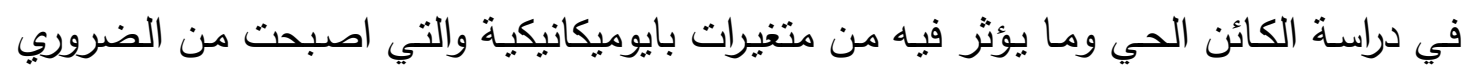

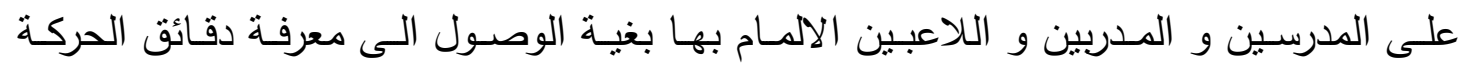

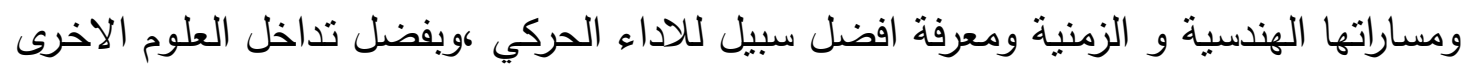

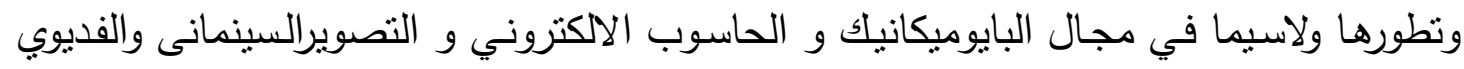

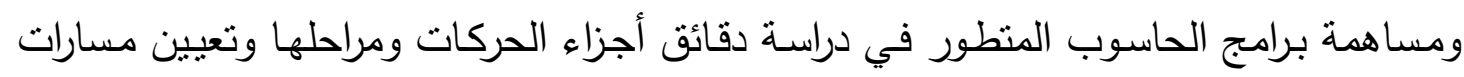

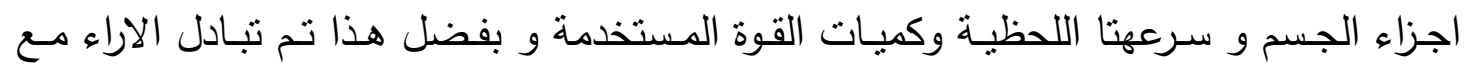

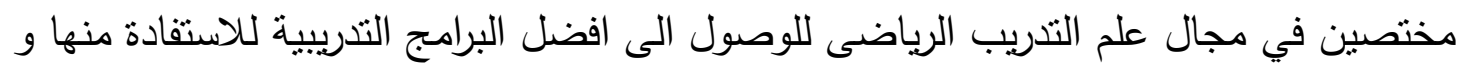

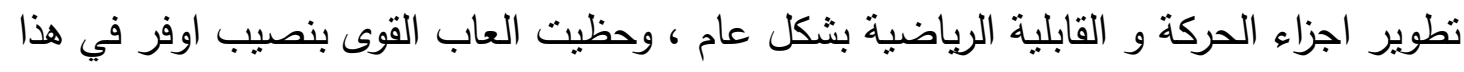
النطور و سيما في مجال الرمي.

تعد مسابقة رمي الرمح شكلا خاصا يختلف عن مسابقات الرمي والدفع اذ يتميز بطابع

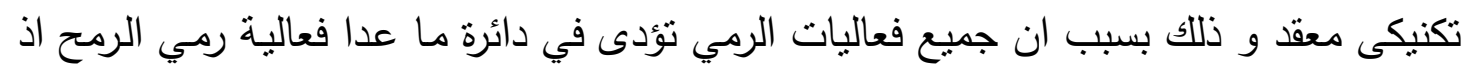

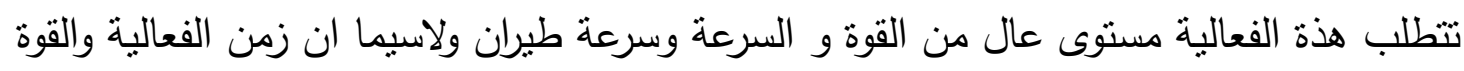

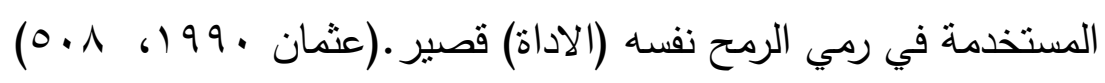

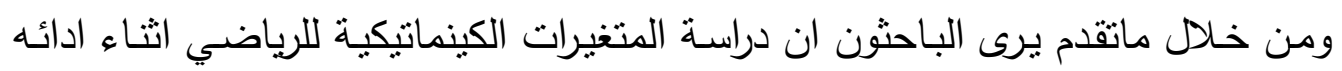

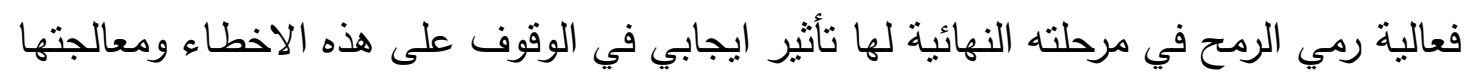

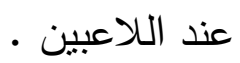

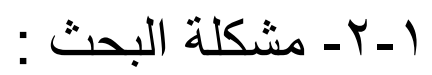

ان تطورا كبيرا طرأ على العاب القوى في العالم و لاسيما في فعالية رمي الرمح لم تأتي

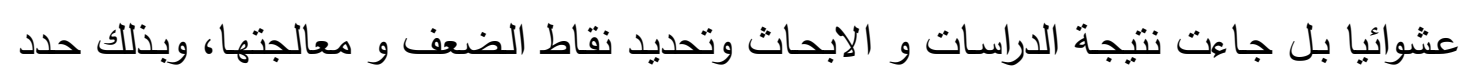

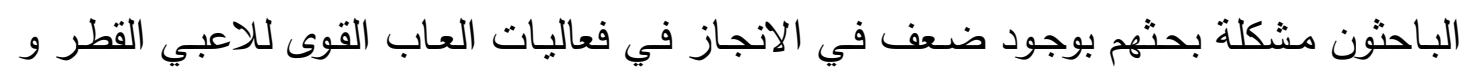

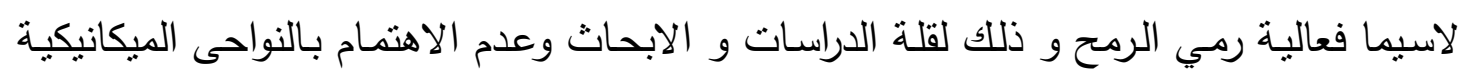

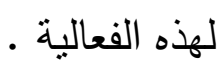


1. التعرف على قيم بعض المتغيرات البايوكينماتيكية في فعالية رمي الرمح r. التعرف علي العلاقة بين قيم بعض المتغيرات البايوكينماتيكية والانجاز .

$$
\text { : }
$$

- توجود علاقة ارتباط دالة احصائيابين قيم بعض المتغيرات البايوكينماتيكية والاتجاز .

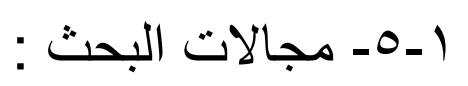

- المجال البشرى : لاعبو الرمح الاوائل المشاركين في بطولة شباب القطر بالعاب القوى .

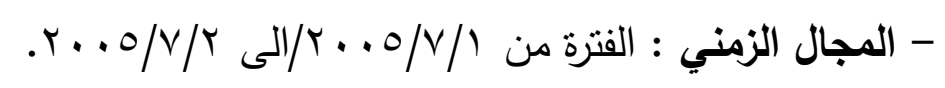

- المجال مكانى : ملعب نادي اربيل الرياضي ل

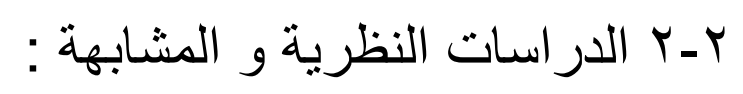

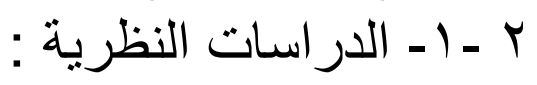

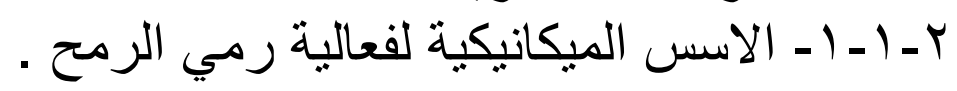

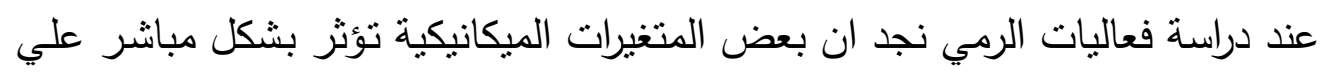

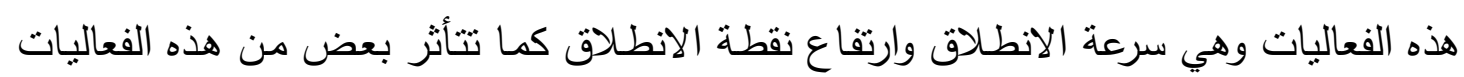

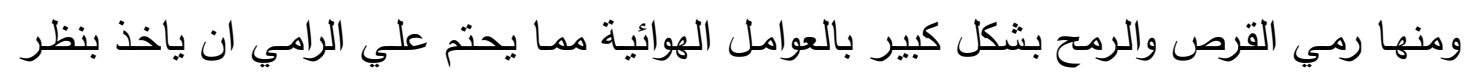

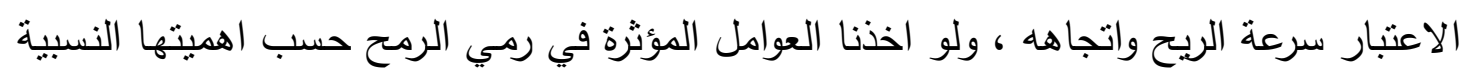

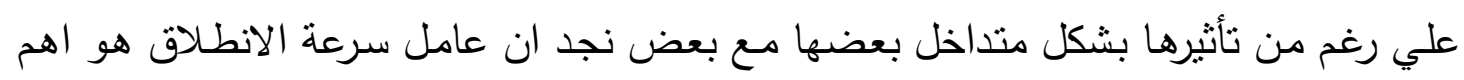

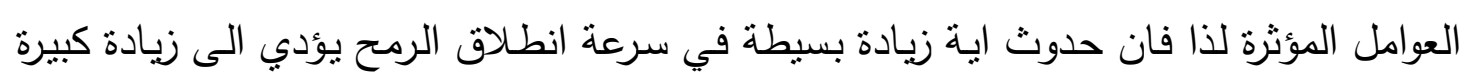

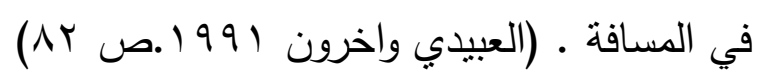

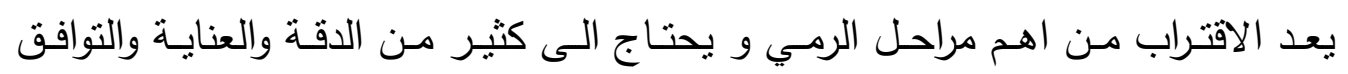

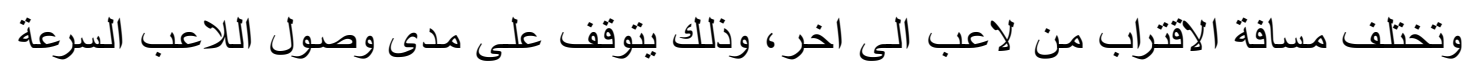

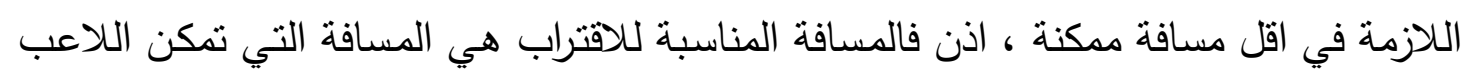

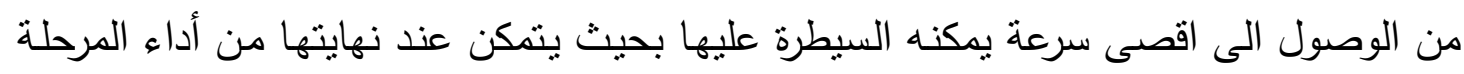

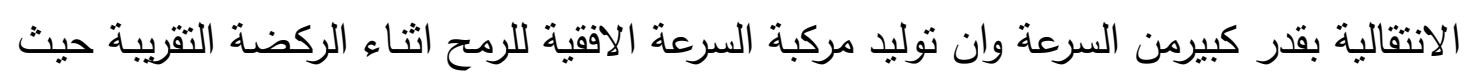

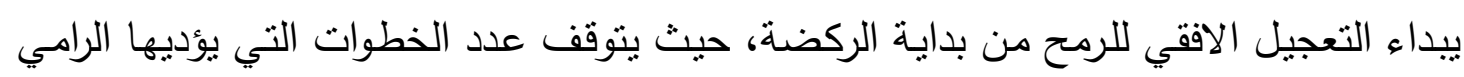

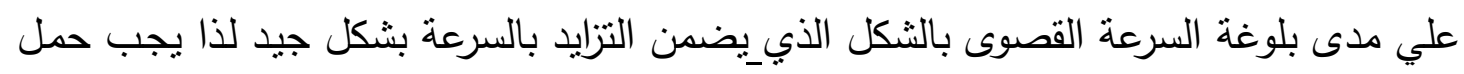

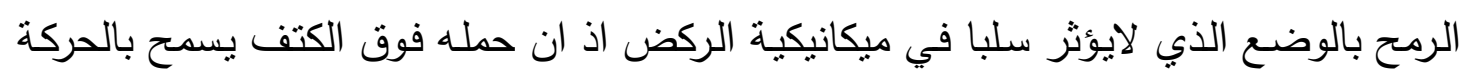

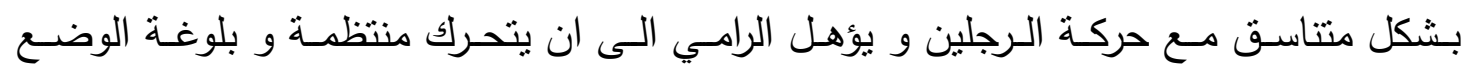


الصحيح للرمي ولاسيما اثناء تهيئة الرمح خلال الخطوات الاخيرة من الاقتراب .(مجيد والاتصار ( rVA ص. r... r

وتعد زاوية الانطلاق العامل الثاني في الاهمية بعد سرعة الانطلاق حيث تعتمد المسافة بشكل كبير على الزاوية التى ينطلق منها الرمح ، وهناك اراء ودراسات كثيرة حول الزاوية التهاية المثالية

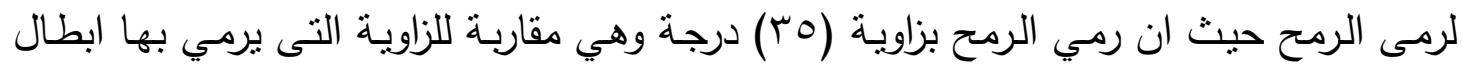

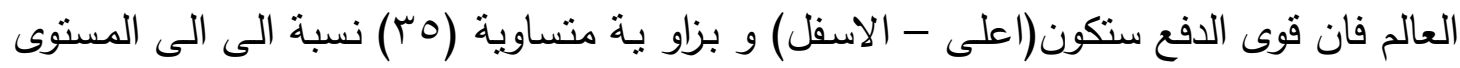

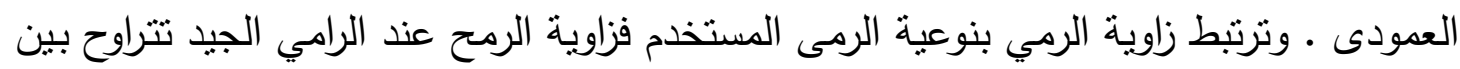
(rی-rV)

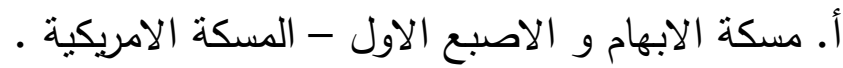

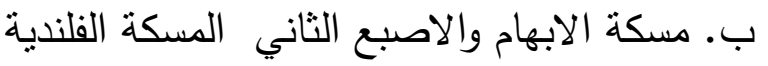

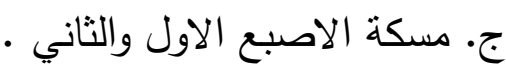

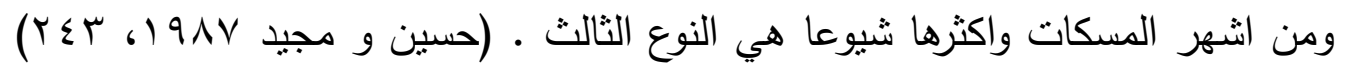
ان استمرار الرامي بكامل سرعته التى اكتسبها خلال الركضة التقريبة هو المتغير الميكاع الميكانيكي

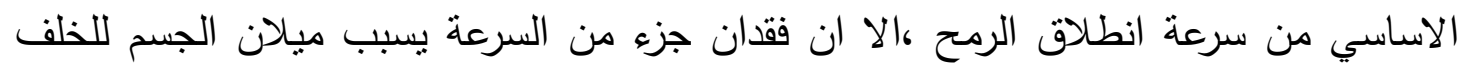

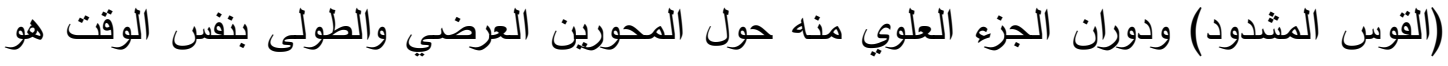

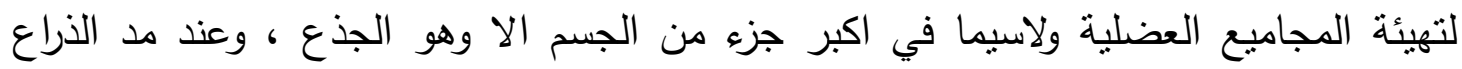
للخلف يتم استثمار القوى المتولدة عن مجموعة عضلات الصدر والكتف والظهر العلوية الخلفية

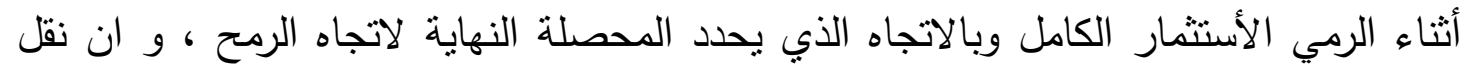

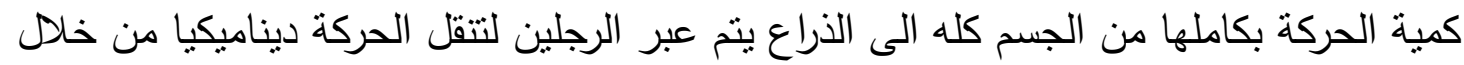

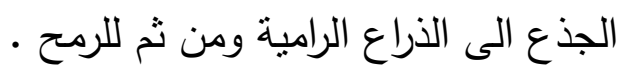

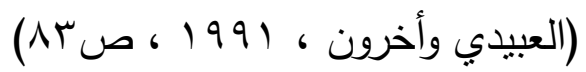

ان التغيير الميكانيكى لوضع جسم الرامي اثناء لحظة الاخيرة للرمي تكون فية الخطوة

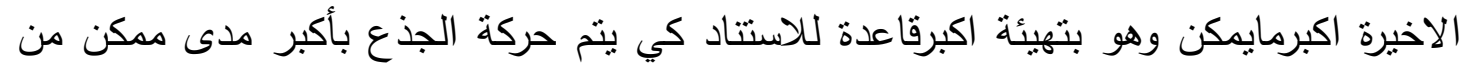

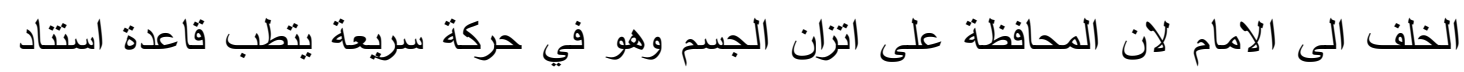
كبيرة كي تتساوى عزوم القوى المؤثرة على الجسم و تؤثثر قوة اندفاع الجسم الى الآلى الامام بعزمها

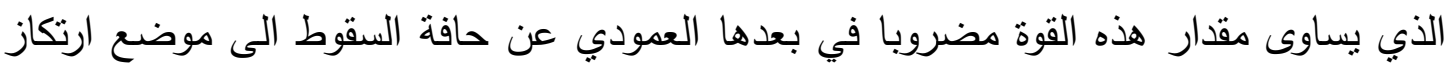

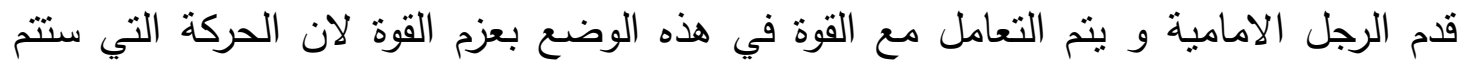

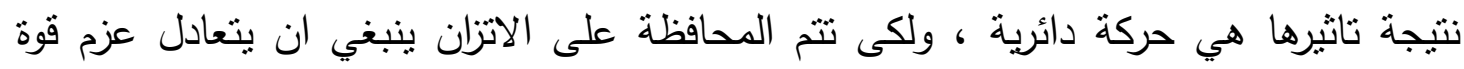

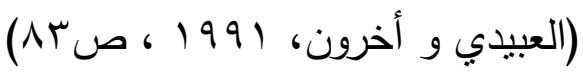

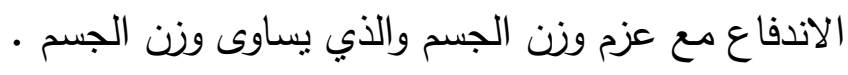




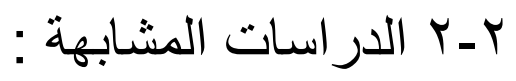

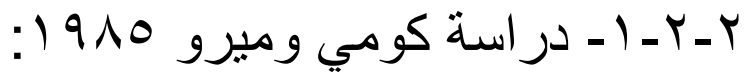

"التحليل البيوميكانيكى لرياضي رمي الرمجح"

- هدف البحث : مقارنة نسبة الخصائص الميكانيكية لكل من الرماة و الراميات في الرمح و وليكي

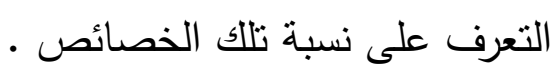

- منهج البحث: استخذم الباحثان الدنهج الوصفى لمقارنة الننائج.

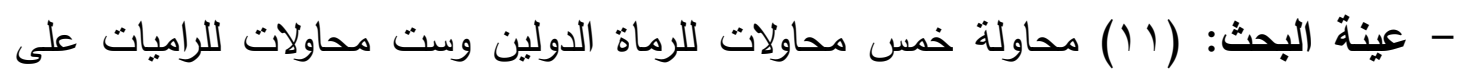

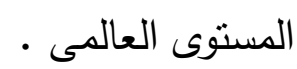

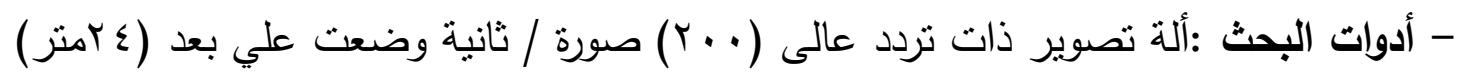

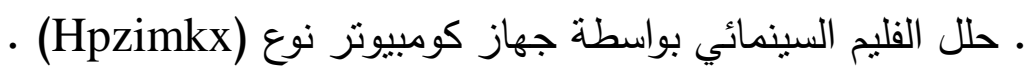

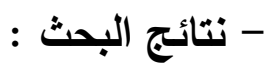

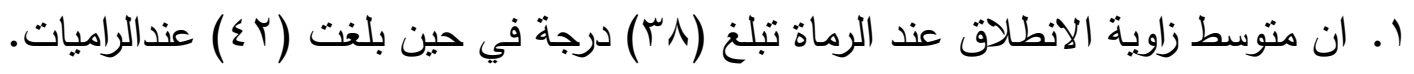

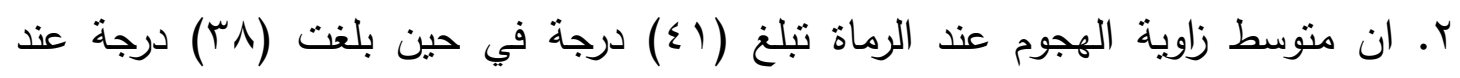
الراميات.

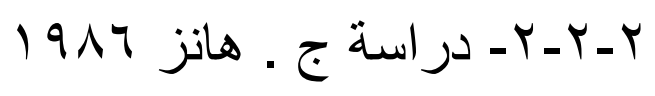

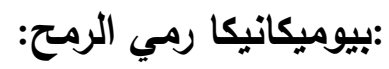

- هدف البحث :تحليل المراحل الاربعة لرمي وتحديد أهم الدتغيرات البيوميكانيكية المؤثرة .

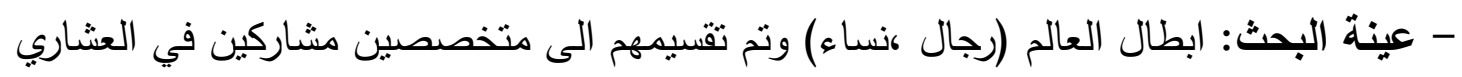
والخماسي • بلغ عدد افراد عينة البحث (1) (1).

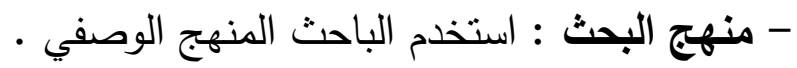

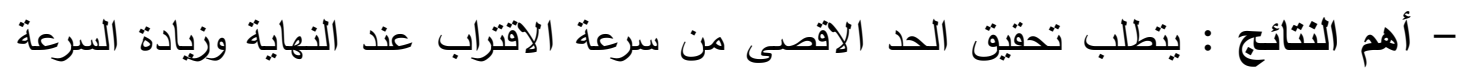

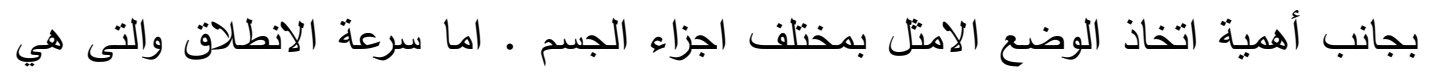

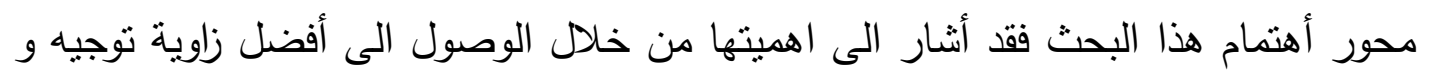

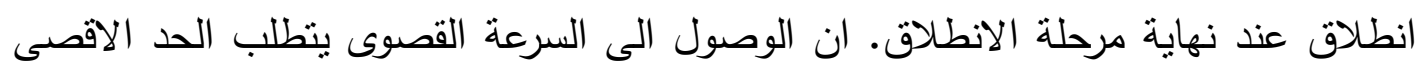

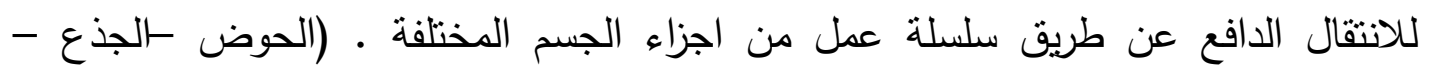




$$
\text { r- بـ اجر اءع ات البحث: }
$$

استخدم الباحثُن المنهج الوصفى بالاسوب المسحى لملاعمته لطبيعة مشكلة البحث

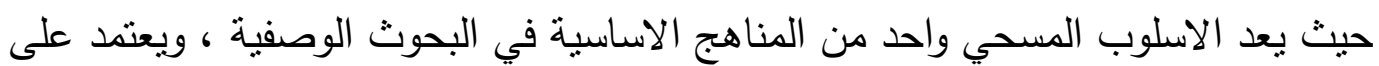

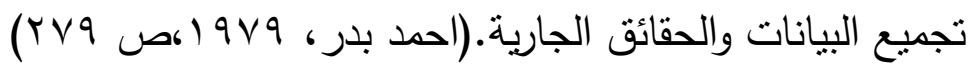

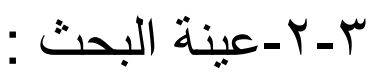

اجري البحث علي عينة عمدية تكونت من (0) لاعبين من فئة شباب القطر والذين

\begin{tabular}{|c|c|c|c|}
\hline الانجاز & ن ل & الاسم & $ت$ \\
\hline or, ro & ديوانية & حسين نايف & 1 \\
\hline OY,Y. & بشكه وتن & سامان محمد & r \\
\hline$\leqslant \wedge, 1$. & بصرة & عبدالعزيز عبدالمجيد & r \\
\hline$\varepsilon V, Y_{0}$ & كاروان & صهيب أحمد & $\varepsilon$ \\
\hline$\leqslant r, 10$ & بشمه ركه & بختبار ميرزا & 0 \\
\hline
\end{tabular}

حصلوا علي افضل (0) مراتب متقدمة في السباق .

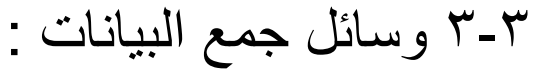

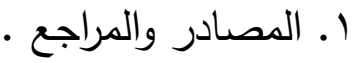

بـ الاجهزة والادوات

r-ب ا الاجهزة و الادو ات المستخدمة في البحث :

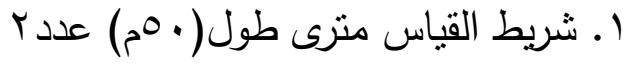

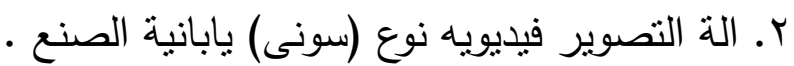

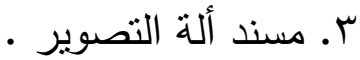

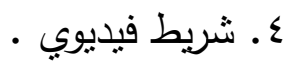

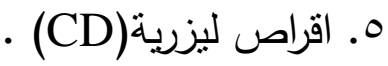

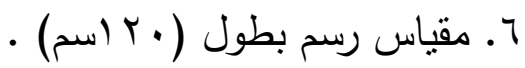

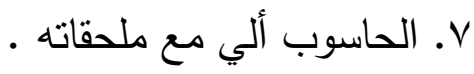

1. 1مح قانوني عدد(0) 


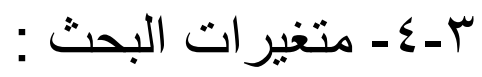

اعتمد الباحثون علي عدد من المتغيرات البايوكنيماتيكية وذللك حسب اهميتها بوصفها

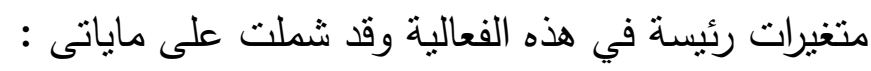

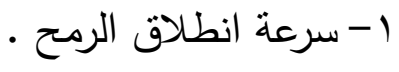

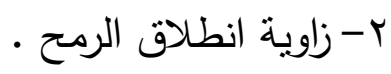

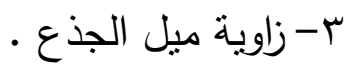

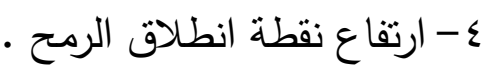

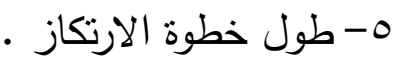

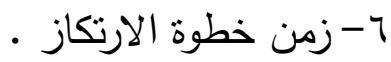

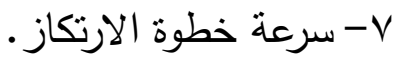

1- السرعة الزاوية لليد الرامية .

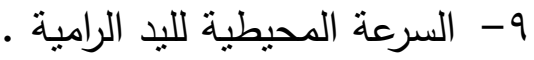

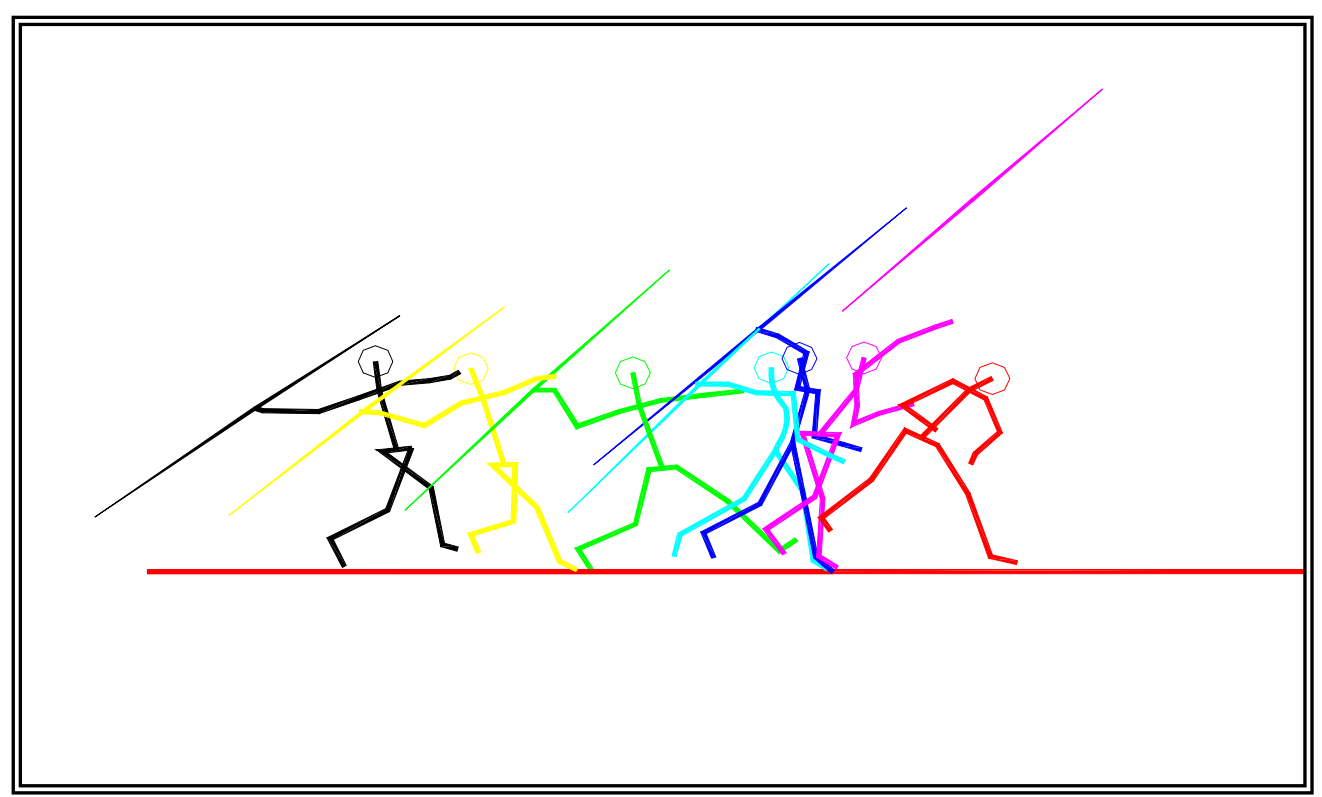

شكل (1)

المرحلة النهائية لفعالية رمي الرمح

بـ الملاحظة العلمية التقنية :

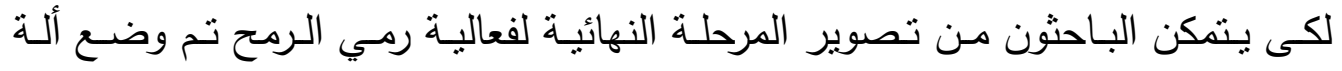

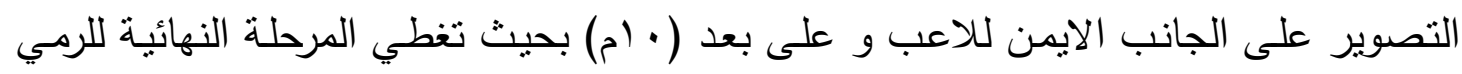

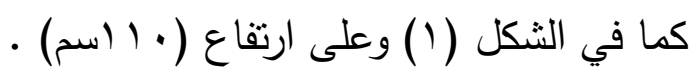


ب-7 البر امج المستخدمة فى التحليل :

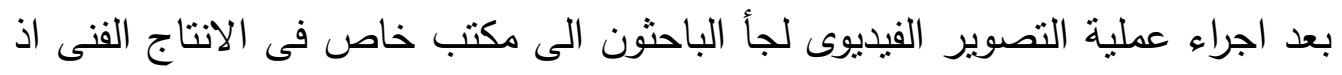
قام بتحويل الافلام الفديوية الى اقراص ليزرية CD بعدها قام الباحثون باستخدام البرامج الاتية التئ

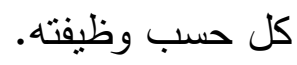

I ا برامج Iflima : يمكن من خلال هذا البرامج نقطيع اجزاء الفلم الى اجزاء صغيرة وحسب

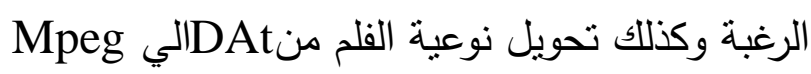

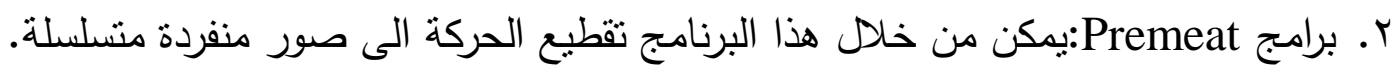

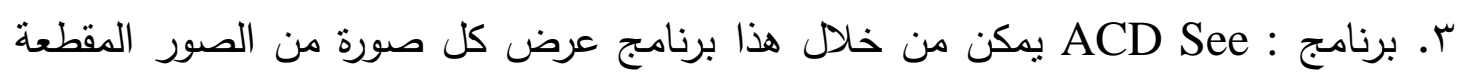

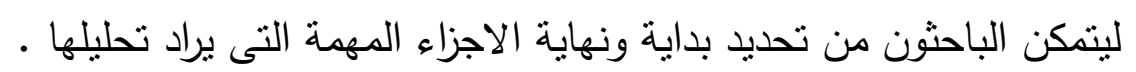

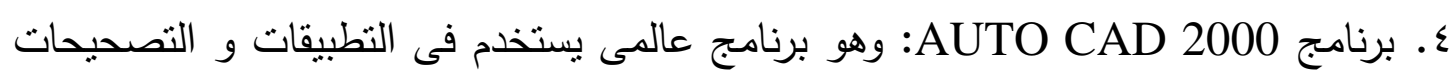

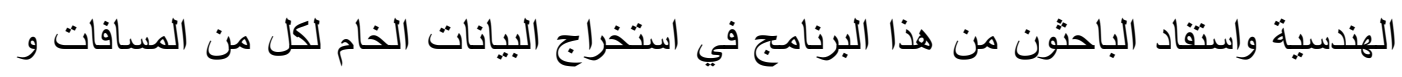

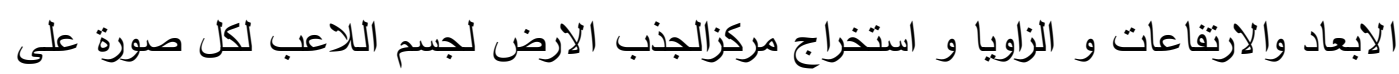
حدى. 0. برنامج Excel: وهو احد برامج Office واستفاد الباحثون من هذا البرنامج فى معالجة

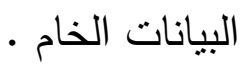

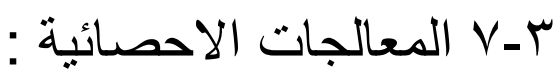

استخدم الباحثون المعالجات الاحصائية الاتية :

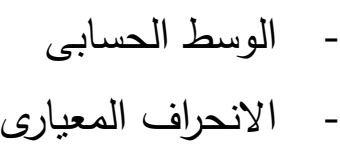

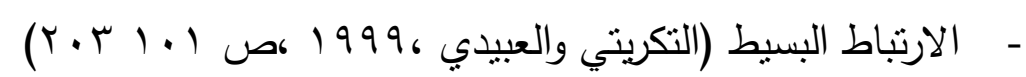
- - وقدم تم استخدام الحاسوب الالى لغرض معالجة البيانات احصائيا باستخدام برنامج (Spss) 
ع - عرض النتائج و تحليلها ومناقشتها ع - ا عرض النتائج وتحليلها ـ ـ ـ ا - عرض و و تحليل نتائج متغير ات الانطلاق و علاقتها بالانجاز

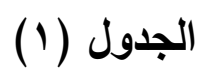

يبين العلاقة بين كل من (السرعة ،الزاوية ، ارتفاع) نقطة انطلاق للرمح مع الانجاز

\begin{tabular}{|c|c|c|c|c|c|}
\hline قيمة (ر) & \multicolumn{2}{|c|}{ الانجاز (م) } & \multicolumn{2}{|c|}{ المتغيرات } & \multirow{2}{*}{ المتغيرات } \\
\hline المحتسبة & $\varepsilon^{ \pm}$ & س س & $\varepsilon^{+}$ & س & \\
\hline$*, 9 \leq$ & \multirow{3}{*}{$r, v$} & \multirow{3}{*}{$\Lambda, \vee$} & $1, \leqslant 9$ & $1 \wedge, \wedge T$ & سرعة انطلاق الرمح م/ث \\
\hline$\cdot, 09$ & & & $\varepsilon$ & r & زاوية انطلاق الرمح \\
\hline$\cdot, \vee \vee 9$ & & & $\cdot, 110$ & 1,79 & $\begin{array}{c}\text { ارتفاع نقطة الانطلاق } \\
\text { (م) }\end{array}$ \\
\hline
\end{tabular}

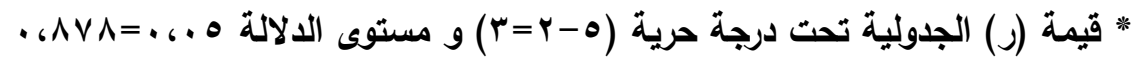

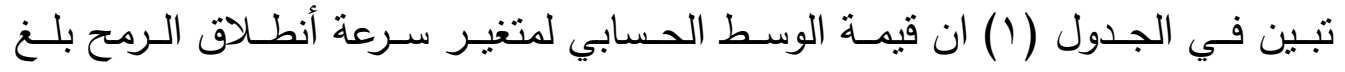

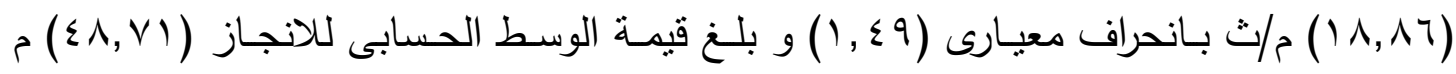

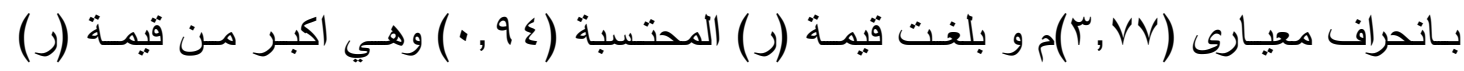

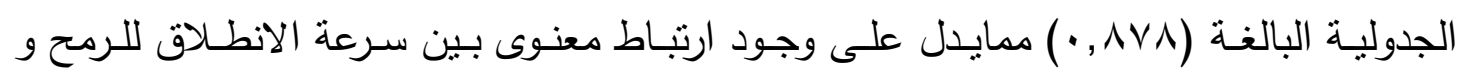

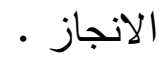

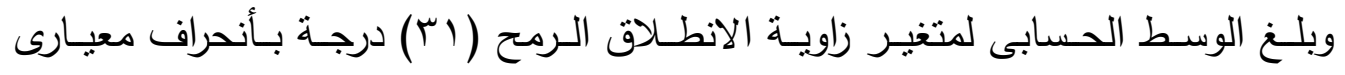

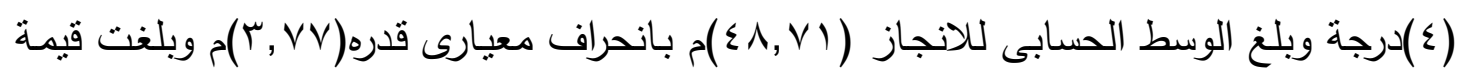

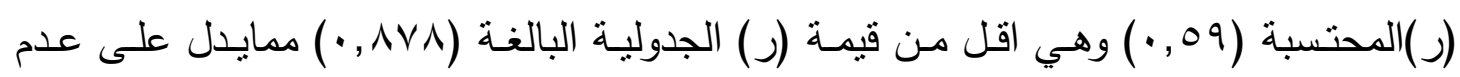
وجود ارتباط معنوى بينهما .

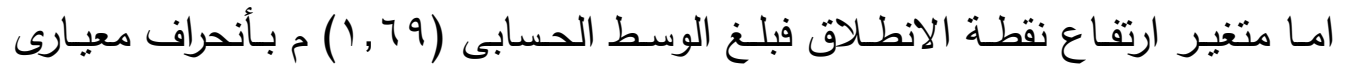

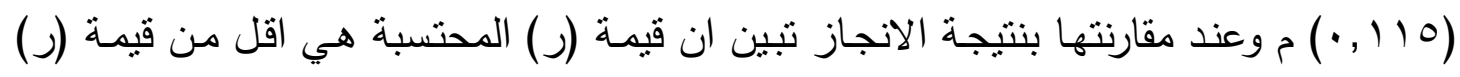
الجدولية مما يدل على عدم وجود ارتباط معنوي بينهما . 
ـ ـ ـ- - عرض و تحليل النتائج منغيرات خطوة الارتكاز و علاقتها

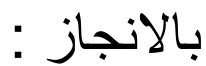

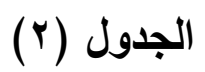

يبين العلاقة بين كل من (طول وزمن و سرعة) خطوة الارتكاز مع الانجاز

\begin{tabular}{|c|c|c|c|c|c|}
\hline \multirow{2}{*}{ قالمحتسبة (ر) } & \multicolumn{2}{|c|}{ الانجاز (م) } & \multicolumn{2}{|c|}{ خطوة الارتكاز } & \multirow{2}{*}{ المتغيرات } \\
\hline & $\varepsilon^{+}$ & س & $\varepsilon^{+}$ & س & \\
\hline$\cdot, 99$ & & & $\cdot, 11 \mathrm{~V}$ & T, & طول خطوة الارتكاز \\
\hline$\cdot, 90$ & $r, v V$ & $\{\wedge, \vee \backslash$ & $\cdot, \cdot, \leqslant 7$ & Tr & زمن خطوة الارتكاز \\
\hline .99 & & & $\cdot, 1 \times 0$ & $r$ rar & سرعة خطوة الارتكاز \\
\hline
\end{tabular}

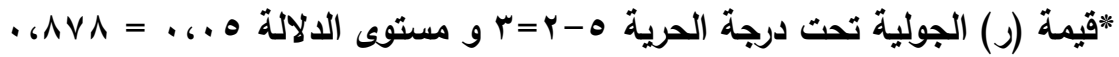

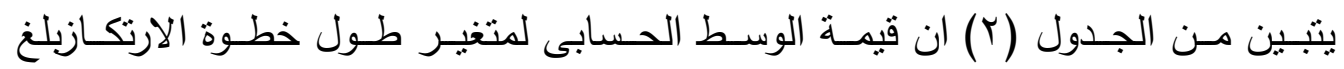

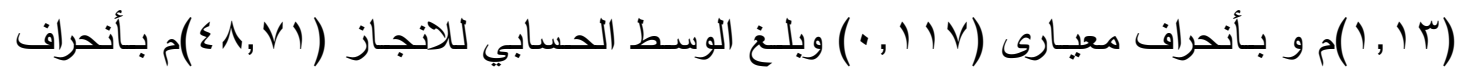

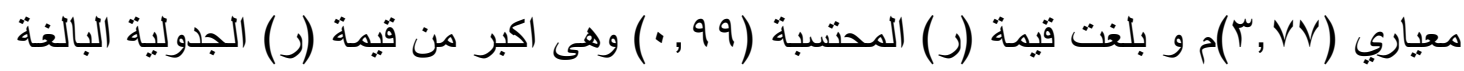

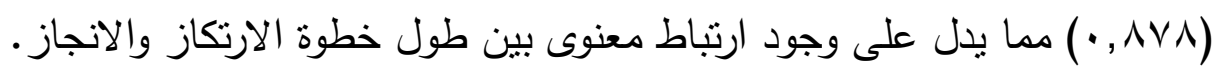

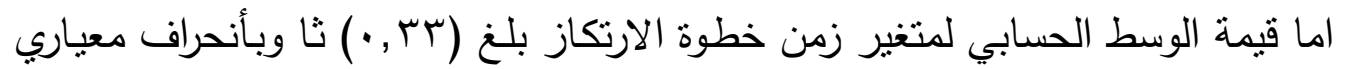

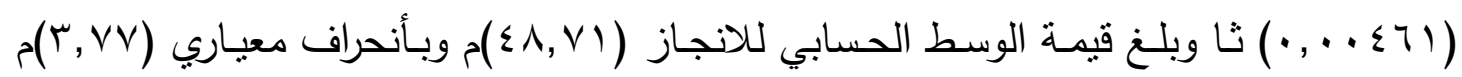

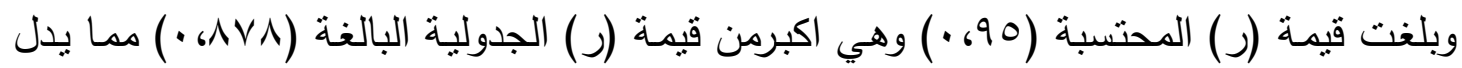
على وجود ارتباط معنوي بين من خطوة الارتكاز الانجاز ـ

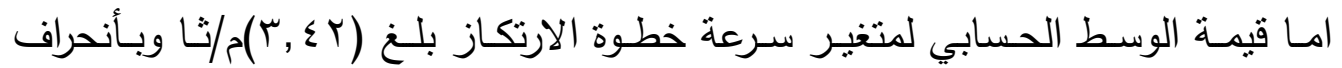

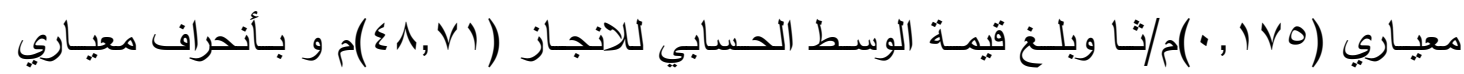

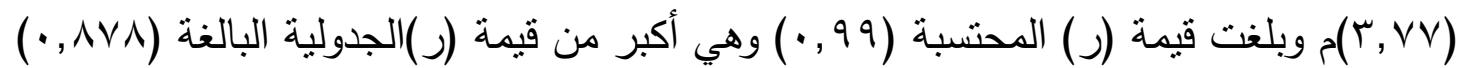
مما يدل وجود ارتباط معنوي بين متغير سرعة خطوة الارتكاز و الانجاز . 
ـ - ا-T عرض و و تحليل نتائج متغيرى سرعة زاوية و سرعة المحيطية

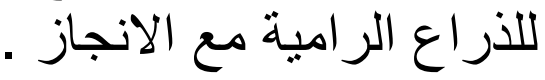

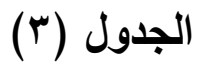

يبين العلاقة بين كل من(السرعة الزاوية ،السرعة المحيطية) للأراع الرامية مع الانجاز

\begin{tabular}{|c|c|c|c|c|c|}
\hline \multirow{2}{*}{ قالمتسبة (ر) } & \multicolumn{2}{|c|}{ الانجاز (م) } & \multicolumn{2}{|c|}{ خطوة الارتكاز } & \multirow{2}{*}{ المتغيرات } \\
\hline & $\varepsilon^{+}$ & س - l l l & $\varepsilon^{ \pm}$ & سَ & \\
\hline$* \cdot, 991$ & \multirow{2}{*}{$r, v V$} & \multirow{2}{*}{$\wedge, V$} & ro,17 & $19 \lambda, r \mu$ & الرامية (درجة/ث) للذراع) \\
\hline$\because \cdot 90$ & & & $r \cdot, 99$ & 150,04 & 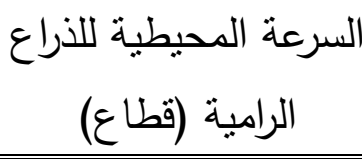 \\
\hline
\end{tabular}

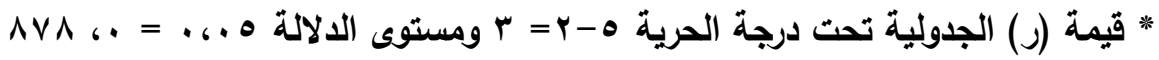

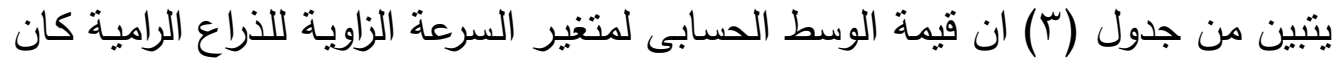

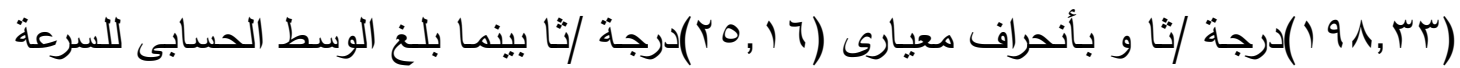

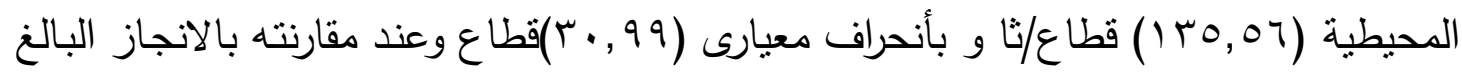

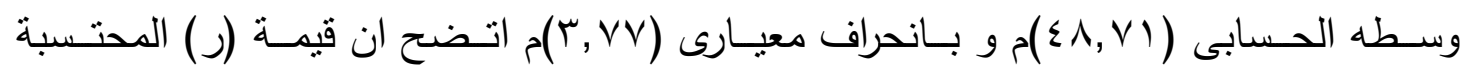

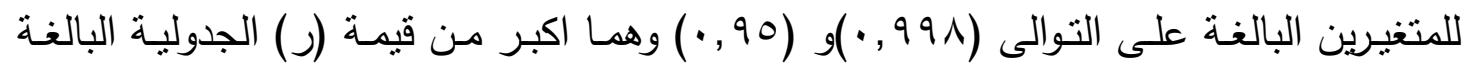

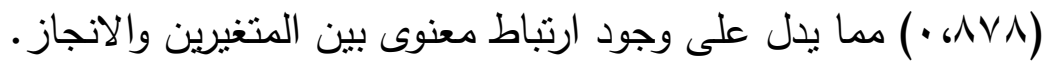

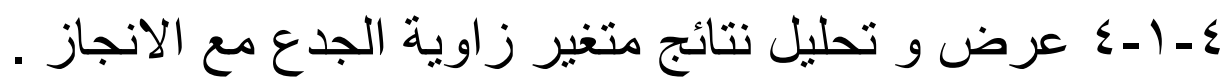

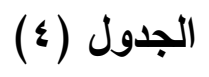

يبين العلاقة بين زاوية ميل الجذع مع الانجاز

\begin{tabular}{|c|c|c|c|c|c|}
\hline قيمة (ر) & \multicolumn{2}{|c|}{ الانجاز (م) } & \multicolumn{2}{|c|}{ خطوة الارتكاز } & \multirow{2}{*}{ المتغيرات } \\
\hline المحتسبة & $\varepsilon^{ \pm}$ & س & $\varepsilon^{ \pm}$ & س & \\
\hline$\cdot, \vee \vee 99$ & $r, v r$ & $\{\lambda, \vee\rangle$ & $r, v \uparrow \Lambda$ & 1.9 & زاوية ميل الجذع (درجة) \\
\hline
\end{tabular}

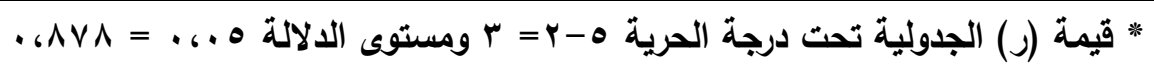

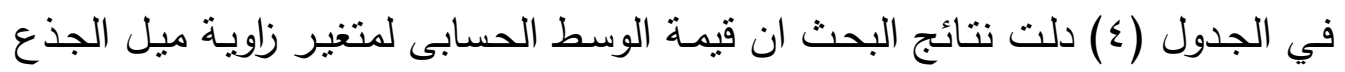

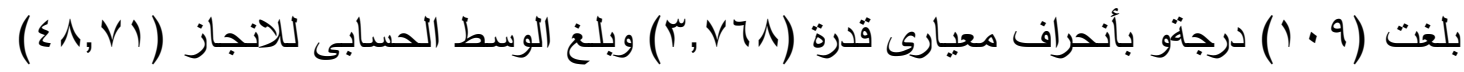

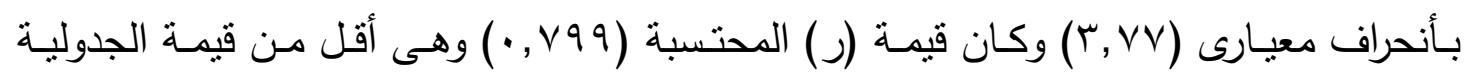
البالغة (AVA, · ) مما يدل على عدم وجود أرتباط معنوى بين زاوية ميل الجذع والانجاز . 
ان الهدف الميكانيكى لفعاليات الرمى هو تحقيق ابعد مسافة افقية ممكنة مع توفر

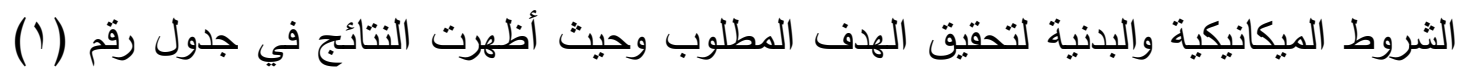

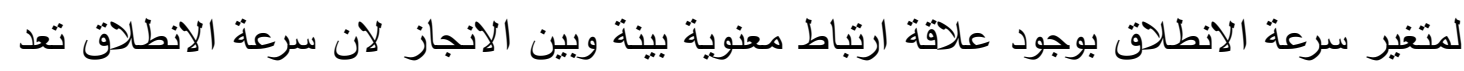

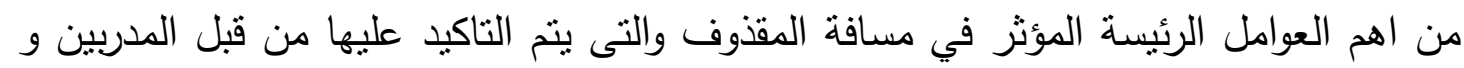

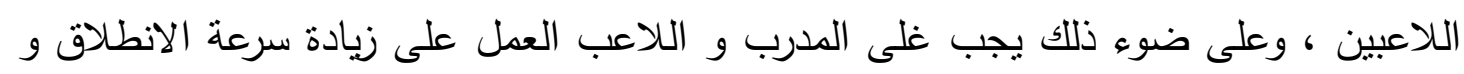

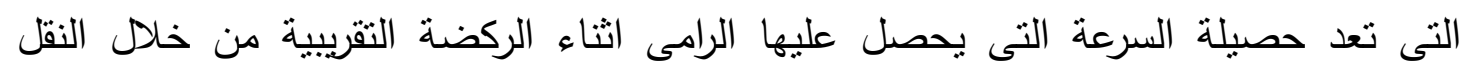

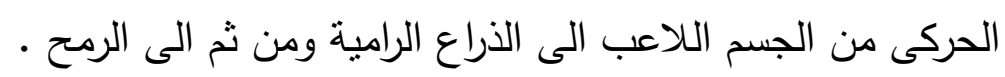

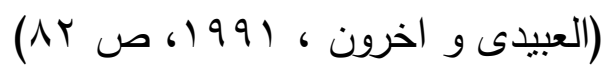

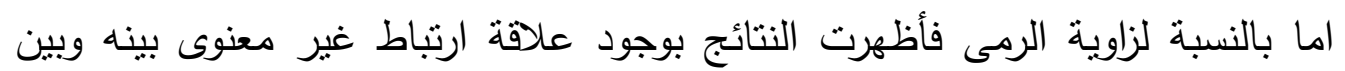

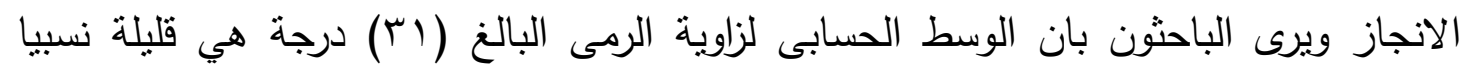

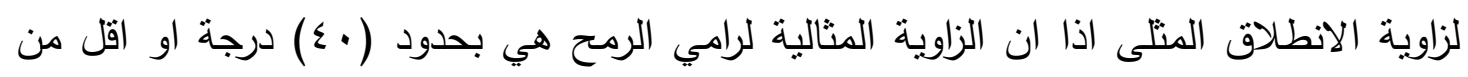

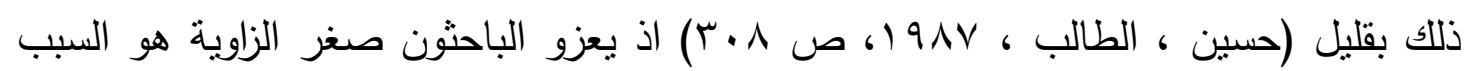

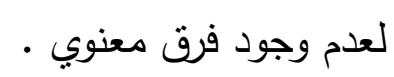

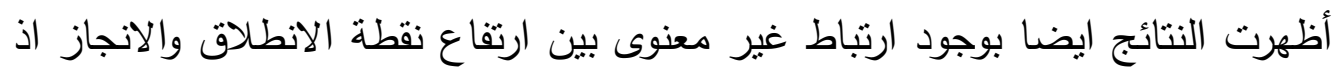

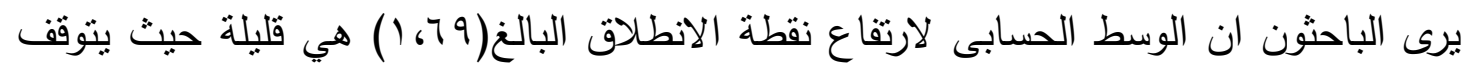

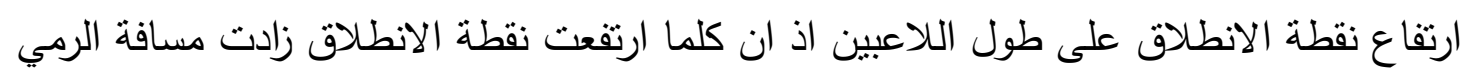

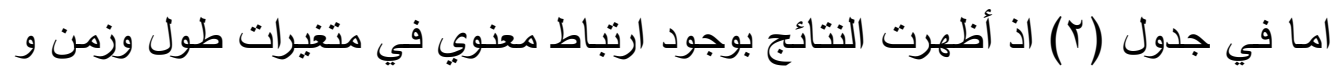

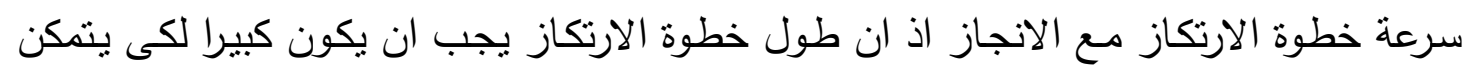

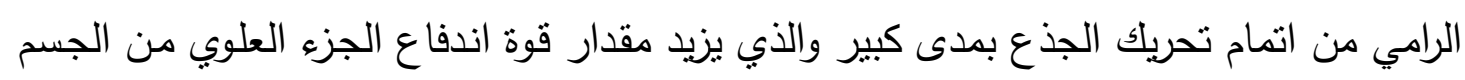

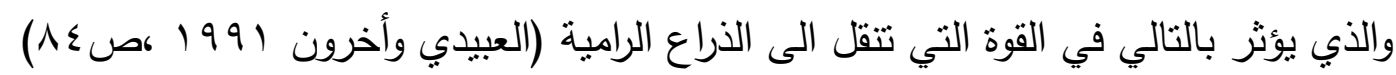

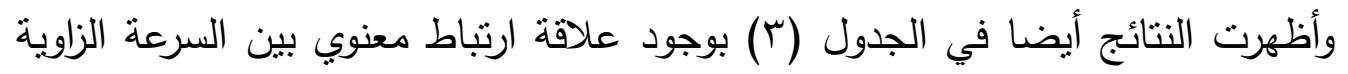

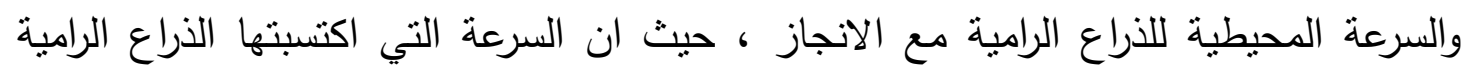

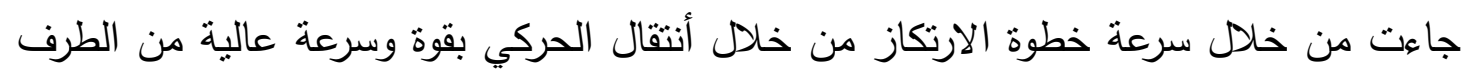

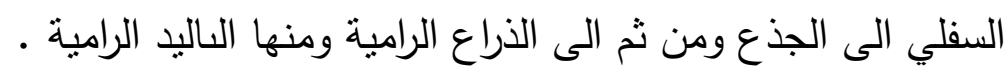

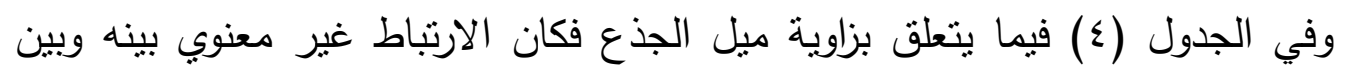

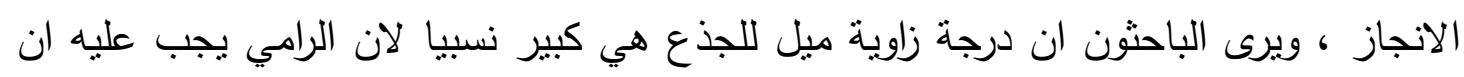

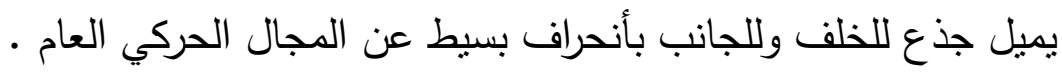

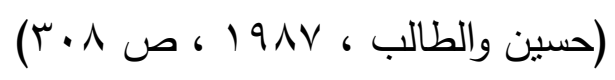




$$
\begin{aligned}
& \text { 0ـالاستتناجات و التوصيات : } \\
& \text { ــ الاستتناجات : }
\end{aligned}
$$

من خلال تحليل النتائج و مناقشتها توصل الباحثُون الى الاستتناجات الاتية :

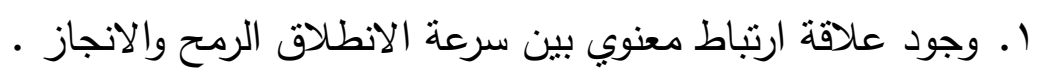

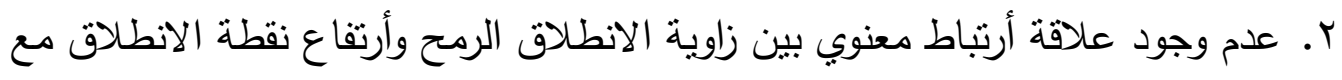
• - الانجاز

r. وجود علاقة أرتباط معنوي بين كل من (طول و زمن وسرعة) خطوة الارتكاز مع الانجاز •

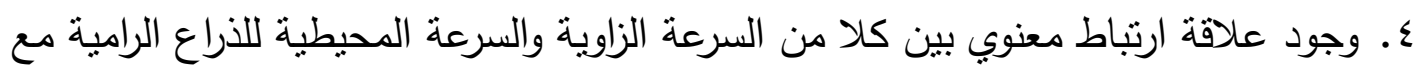

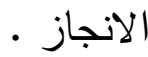
๑. عدم وجود علاقة ارتباط معنوي بين زاوية ميل الجذع و الانجاز • الآر : Y-O (التوصبات في ضوء النتائج التي تم التوصل اليها وضع الباحثون عدة نوصيات يأمل الافادة منها وهى: ا ـ ضرورة تأكيد المدربين واللاعبين على أهمية بعض المتغيرات البايوكينماتيكية كسرعة

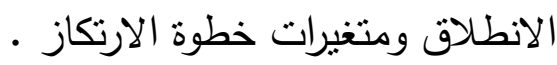
r. اجراء التحليل الحركي على الاداء الفني و بشكل دوري لمعرفة مدى التطور وتقويم الاخطاء r. اجراء دراسات اخرى مشابهة على فعاليات العاب القوى (رمي القرص قذف الثقل رمي (المطرقة). 


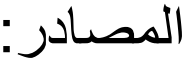

1. بدر ، أحمد : أصول البحث العلمى والمناهجة ، الكويت ، وكالة المطبوعات ، 19V9.

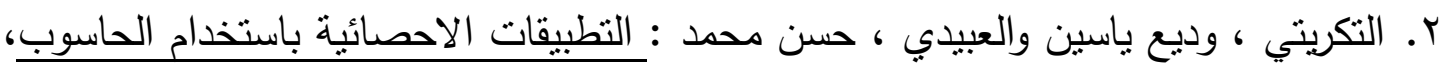

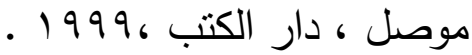

r. حسين ، قاسم حسن و ، طالب ، نزار مجيد : الأسس النظرية والميكانيكية في التثريب

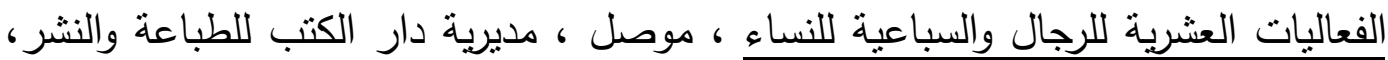
$.19 \Lambda \mathrm{V}$

ع. العبيدي ، صائب عطية وأخرون : الميكانيك الحيوية التطبيقية ، دار الكتب للنشر ، .1991

0. عثمان ، محمد : الموسوعة في العاب القوى ، كويت ، دار القلم ، .199.

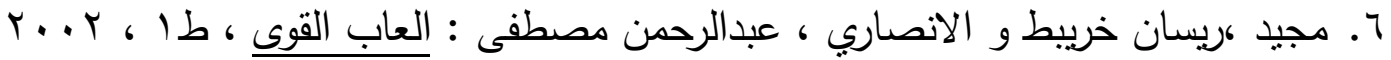

7. Komy ,Hero, Theanalysis of biomecaniks of javelim thrower, 1985 .

8. J.Hanz, The biomecaniks of javelim thrower, 1986. 